\title{
The Histological Effect of Aqueous Ginger Extract on Kidneys and Lungs of Diabetic Rats
}

\author{
Maisa.M.A. Al-Qudah ${ }^{1}$,Ezz Al-Dein Al-Ramamneh ${ }^{2}$, Moawiya A. Haddad ${ }^{3}$ \& Amal Al-Abbadi ${ }^{4}$ \\ ${ }^{1}$ Department of Medical Laboratory Sciences, Faculty of Science, Al-Balqa Applied University, Al-Salt, Jordan \\ ${ }^{2}$ Department of Agricultural Sciences, AL-Shouback University College, Al-Balqa Applied University, Maan, \\ Jordan \\ ${ }^{3}$ Department of Nutrition and Food Processing, Faculty of Agricultural Technology, Al-Balqa Applied University, \\ Al-Salt, Jordan \\ ${ }^{4}$ Department of Plant production and protection, Faculty of Agricultural Technology, Al-Balqa Applied \\ University, Al-Salt, Jordan \\ Correspondence: Maisa M. A. Al-Qudah, Department of Medical Laboratory Sciences, Faculty of Science, \\ Al-Balqa Applied University, Al-Salt 19117, Jordan. E-mail: q.maisa@yahoo.com
}

Received: August 1, 2018

Accepted: August 14, 2018

Online Published: September 11, 2018

doi:10.5539/ijb.v10n4p23

URL: https://doi.org/10.5539/ijb.v10n4p23

\begin{abstract}
Diabetes is a disorder affecting various-aged humans and which can with time cause serious problems for the patient. Medicinal plants are known for their hypoglycemic effects; and among which is ginger (Zingiber officinale) known also for its culinary uses. This study, therefore, was undertaken to evaluate the histological effect of 21-day treatment of aqueous ginger extract used at $500 \mathrm{mg} / \mathrm{kg} \mathrm{BW}$ on female diabetic rats. Fifteen female albino rats were divided into three groups; Group I: control, Group II: non-treated diabetic, and Group III: ginger extract-treated diabetic rats. The ginger extract-treated diabetic group received the daily dose orally for three weeks. Results show that organ weight was not significantly changed. Light microscopic examination of $5 \mu \mathrm{m}$ sections of extract-treated Kidney and Lung of the diabetic rats revealed approximately normal histological structure compared with the untreated ones. The normal appearance of glomeruli and alveoli as well as the normal alveolar wall assumed the ameliorative effect ginger aqueous extract could have on kidney and lung of diabetic rats. These results indicated that this dose of ginger extract may be effective in the treatment of diabetic rats.
\end{abstract}

Keywords: Ginger, Zingiber officinale, diabetic rats, histology, glomerulus, alveoli, light microscopy

\section{Introduction}

Ginger (Zingiber officinale) is a member of the family Zingiberaceae. It is used worldwide as a flavoring agent, garnish or spice in addition to its properties as a food preservative agent (Adeniyi and Sanusi, 2014). It contains 3-6\% ash, 3-6\% crude fiber, 6-8 \% fatty acids and triglycerides, $9 \%$ protein and free amino acids, and approximately 50\% carbohydrates (Tang and Eisenbrand, 1992). It contains also essential micronutrients such as copper, magnesium, silicon, potassium and manganese (Adel and Prakash, 2010). It has therefore both culinary and medicinal purposes (Grant, 2000). Research indicated the beneficial effects of ginger as anti nausea, anti microbial (Portnoi et al., 2003), anti pyretic (Suekawa et al., 1984), analgesic, anti inflammatory, hypoglycemic, anti ulcer, antiemetic, cardio tonic, anti hypertensive, hypolipidemic, and anti platelet aggregation in laboratory animals (Ojewole, 2006; Al-Amin et al., 2006).

Many studies reported the hypoglycemic effect of different forms of ginger in both human subjects and laboratory animals. Examples included the use of aqueous extract in alloxan-induced diabetic rats (Jafri et al., 2011) and 6-gingerol or aqueous ginger extract in STZ-induced diabetic rats (Abdulrazaq et al., 2012; Sukalingam et al., 2013).

Ginger was proved more potent renoprotective agent in both acute and chronic renal failure(Mahmoud et al., 2012; Swaroopa, 2013). There are few studies concerning the effect of extracts obtained from this plant alone on lungs and kidney. Therefore, in this study, we tried to investigate and evaluate the histological effect of ginger aqueous extract $(500 \mathrm{mg} / \mathrm{kg} \mathrm{BW})$ on these organs in laboratory diabetic- and non-diabetic- rats. 


\section{Method}

\subsection{Experimental Procedures}

The rhizomes of ginger were purchased from a local market in Amman. The study was approved by the Institutional Review Board of Al-Balqa Applied University. The extract was prepared from $30 \mathrm{~g}$ powder of cleaned dried grinded plant refluxed at room temperature with $100 \mathrm{ml}$ of hot water at $150 \mathrm{rpm}$ for two weeks. Further steps were done to get extract with a concentraion of $1 \mathrm{~g} / \mathrm{ml}$ taking in consideration the starting weight of the plant. The method illustrated by Elshater et al., (2009) was used to prepare the extract. Fifteen healthy adult female albino rats were purchased from the faculty of medicine, University of Jordan. The rats were weighed and randomly divided into three groups containing five rats each: Group I: control, Group II: non-treated diabetic, and Group III: ginger extract-treated diabetic rats. The rats were fastened overnight, then alloxan induced diabetes was obtained by intraperitoneal injection of alloxan monohydrate (Sigma, St. Louis, MO, USA) dissolved in distilled water with a dose of $65 \mathrm{mg} / \mathrm{kg}$ BW (Al-logmani and Zari, 2011). After induction of diabetes, the rats in group III were treated with ginger aqueous extract orally for 21 days. The plant extract was administered as shown in Table 1.

\subsection{Histopathological examination}

After 21 days from the beginning of the experiment, the rats were weighed, sacrificed and dissected. Then the Lungs and kidneys were removed, cleaned, weighed and immediately small pieces of them were taken, fixed in $10 \%$ buffered formaldehyde solution and stored until performing light microscopy technique. Relative organ weights were computed as follows (Bashir et al., 2015): Relative organ weight= organ weight (g)/body weight (g) $\mathrm{x} 100$. The fixed organs were examined by histopathological method. The light microscopy involves preparation of $5 \mu \mathrm{m}$ sections stained with hematoxylin and eosin stain and finally the sections were examined under compound light microscope with 400X magnification. The procedure used in light microscopy is described in earlier in literature (Al-Qudah, 2016; Al-Qudah et al., 2016).

\subsection{Statistical analyses:}

Data were expressed as mean \pm standard deviation. The differences were considered to be significant when $\mathrm{P}$ value was $<0.05$.

\section{Results}

The relative kidney and lung weight of rats were not significantly ( $>0.05)$ different from those of control at the examined extract dose (Table 2). The histopathological examination illustrated the ameliorative effect of ginger aqueous extract on kidney of diabetic rats compared with the control (Figure 1). Figure 1a shows the normal architecture of kidney in control rats; normal glomerulus as well as normal proximal and distal tubules. In contrast Figure $1 \mathrm{~b}$ demonstrates the abnormal histopathological changes in the kidney tissue of diabetic rats including abnormal glomerulus, congestion and necrosis of proximal and distal tubules of the nephron. These histopathological changes were approximately normalized when the diabetic rats were treated with the extract compared with the control (Figure 1c). The glomerulus was found approximately normal as was the proximal and distal tubules.

Table 1. Experimental design: Oral administrations of ginger aqueous extract to different groups of adult female albino rats

\begin{tabular}{lllll}
\hline Duration & Organ studied & Experimental group & Number of rats & Extract dose \\
\hline 21 days & Kidney (K), & I & five Females & Control \\
& Lungs (L) & & & \\
21 days & K, L & II & five Females & Untreated diabetic rats: \\
& & & & 1.injected with $65 \mathrm{mg} / \mathrm{kg} \mathrm{BW}$ of alloxan; \\
& & & 2. received only distilled water.
\end{tabular}


Table 2. Weight of kidney and lungs of rats treated with ginger aqueous extract. The results were expressed as means \pm standard deviation (S.D)

\begin{tabular}{lcc}
\hline Groups & Kidney (g) & Lungs (g) \\
\hline Group I: Non-diabetic Control $(\mathrm{n}=5)$ & $1.60 \pm 0.16$ & $1.60 \pm 0.20$ \\
Group II: Diabetic (n=5) & $1.54 \pm 0.18$ & $1.68 \pm 0.22$ \\
Group III: Diabetic + Dose 500 mg/kg B.W (n=5) & $1.60 \pm 0.25$ & $1.50 \pm 0.46$ \\
\hline
\end{tabular}

Abnormal histological changes in lung of diabetic rats (Figure 2 b) such as thickening in the wall of alveoli and congestion were observed in this study compared with the control (Figure 2a).These changes were approximately diminished when the diabetic rats were treated with the extract (Figure 2c) indicating that the ginger aqueous extract at $500 \mathrm{mg} / \mathrm{kg}$ improves the lung condition, represented in its good effect on the alveoli and its wall as compared with the control.

The results presented in figure 1 and figure 2 represent the results found from all rats.
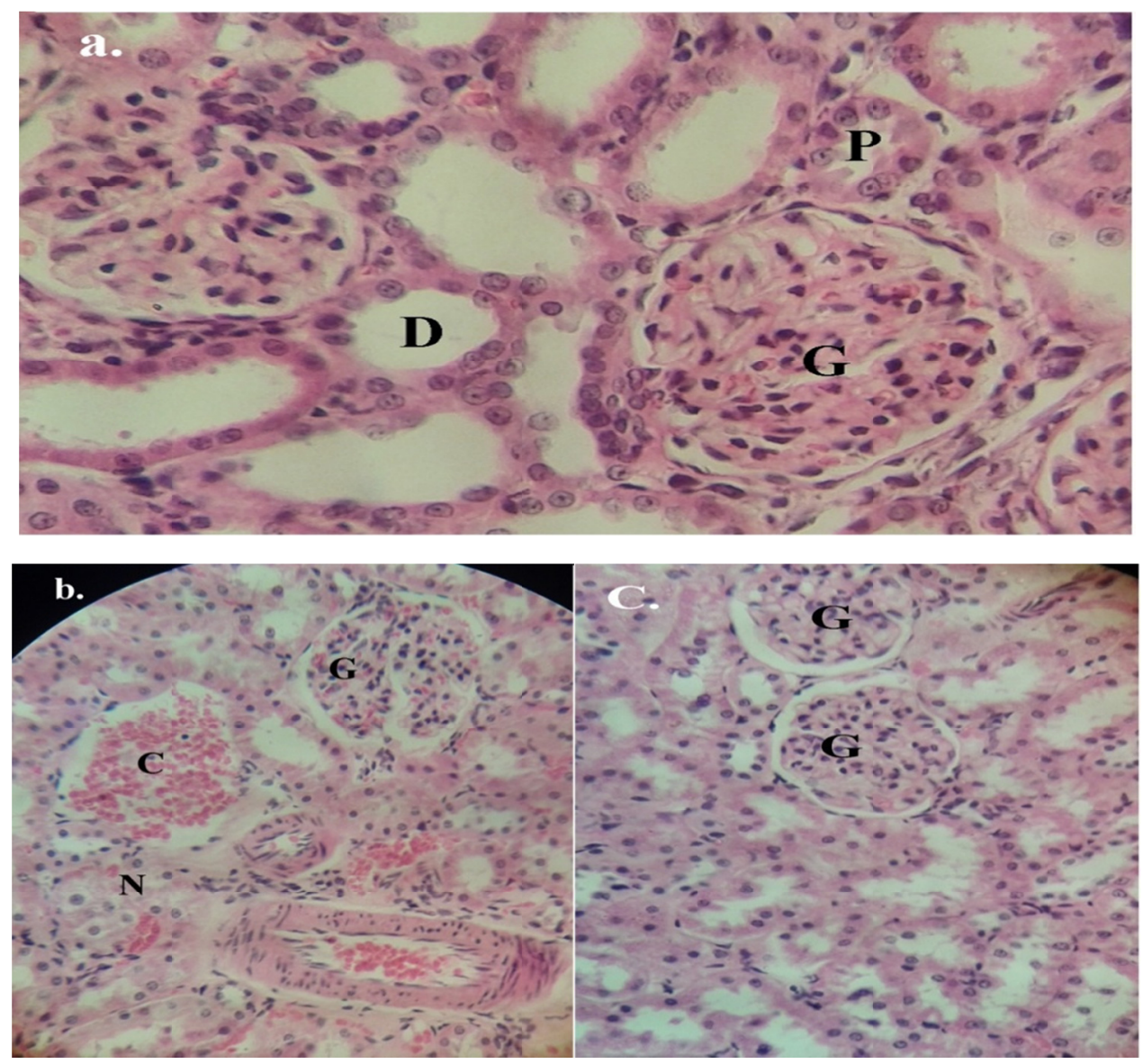

Figure 1. Photomicrograph of nephron parts in rats kidney tissue. a. section of normal structure of kidney from control rat. G: glomeulus, P: proximal tubule, D: distal tubule. (H\&E) stain, 400x. b. section of abnormal histopathological structure of kidney from diabetic rat. C: congestion, G: abnormal glomerulus, N: necrosis of proximal and distal tubules. (H\&E) stain, 400x. c. section of histological structure of kidney from rat treated with $500 \mathrm{mg} / \mathrm{kg}$ BW of extract. G: normal glomerulus (H\&E) stain, 400x 

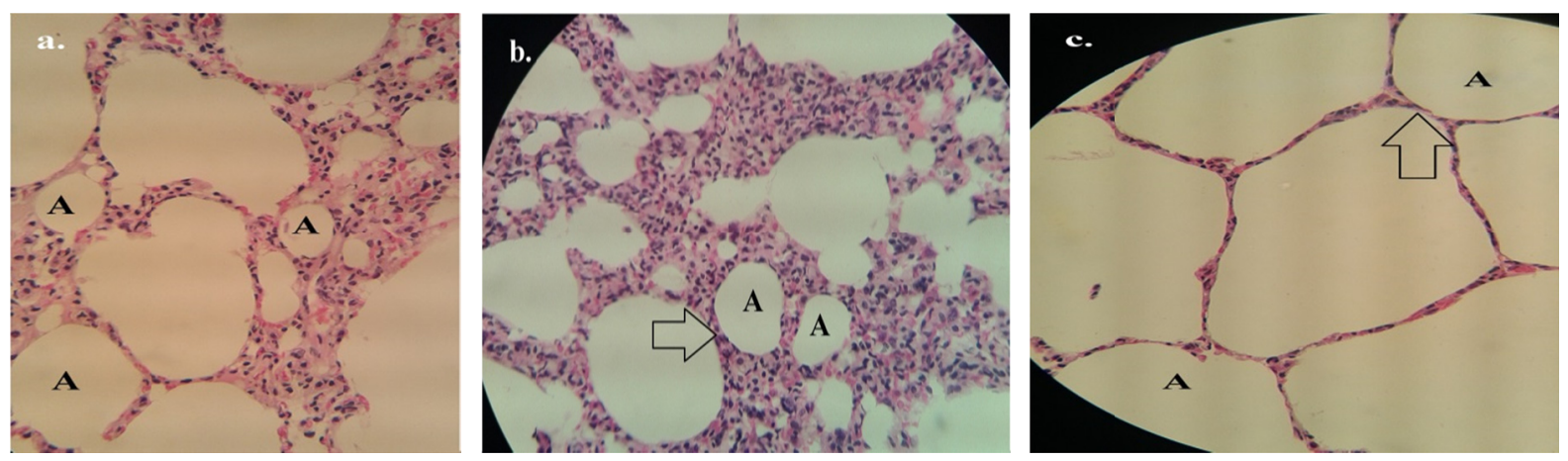

Figure 2. Histopathological investigation of Lung sections of rats. a. control rat with normal lung structures. A: Alveolus. (H\&E) stain, 400x. b. diabetic rat with histolpathological changes in the lung structure. A: alveolus,

Arrow: thick wall of alveolus. (H\&E) stain, 400x. c. diabetic rat treated with $500 \mathrm{mg} / \mathrm{kg} \mathrm{BW}$ extract with approximately normal structure of lung. A: normal alveolus, Arrow: normal wall of alveolus. (H\&E) stain, 400x

\section{Discussion}

The results of the present study revealed that oral treatment of rats with ginger aqueous extract at $500 \mathrm{mg} / \mathrm{kg}$ has normalized the histological structure of kidney. This is in agreement with the study of Rafieian-Kopaei and Nasri (2013), in which sever tubular damage in kidney as well as degeneration of the renal cells induced by gentamicin was reduced Tzeng et al. (2013) treated diabetic rats orally with ginger for 8 weeks and found ameliorative effects on glomerulus and in reducing renal dysfunction and hyperglycemia. In addition, it was reported that ethanolic extract of ginger has therapeutic potential against carbon tetrachloride induced renal injury in rats by normalizing the kidney histopathological structure, and thus improved kidney functions (Hamed and El-Rigal, 2012).

However, the diminishing of abnormal histological changes in treated rats lung is disagree with other studies on rats, in which $500 \mathrm{mg} / \mathrm{kg}$ ginger was found to be slightly toxic when administrated intraperitoneally for 28 days, and where investigation was undertaken for haematological parameter, liver and lung tissues (Al-Naqeeb et al., 2003). Adding to that, administration of $50 \mathrm{mg}$ ginger $/ \mathrm{Kg}$ intraperitoneally in rats was safe while $500 \mathrm{mg} / \mathrm{kg}$ caused a thickened alveolar walls and RBCs aggregating in some alveoli (Al-Naqeeb et al., 2003). On the other hand, ginger was reported to have anti inflammatory property and contains B2 agonist components which makes it benefit in improving lung function and in treating asthma (Elbadri et al., 2011). Owing to its leukotriene inhibiting property, that some studies suggested the potential use of ginger for asthma attacks treatment (Sirvastava and Mustafa, 1992).

Oral or intraperitoneal routes of administration of methanolic or aqueous ginger extracts were used in animal toxicological studies to determine the acute toxicity (Salim, 2014). The oral LD50 in mice was $10.25 \mathrm{~g} / \mathrm{kg}$ for methanolic extract, whereas it was $11.75 \mathrm{~g} / \mathrm{kg}$ for aqueous extract (Shalaby and Hamowieh, 2010). When using ethanolic extract that was administrated intraperitoneally, the LD50 was $1551 \mathrm{mg} / \mathrm{kg}$ (Ojewwole, 2006). A single dose of ginger caused changes in cardiac tissue and severe hypotension in a rat model at $2500 \mathrm{mg} / \mathrm{kg}$ (Elkhishin and Awwad, 2009). Concerning toxicity of repeated dose in rats, Rong et al. (2009) examined the toxicity of 35 days oral administration of powdered ginger, and reported that up to $2 \mathrm{~g} / \mathrm{kg}$ was considered safe for both male and female on the general condition or heamatological parameters.

In Conclusion, daily oral administration of aqueous ginger extract at $500 \mathrm{mg} / \mathrm{kg}$ body weight for 3 weeks could be safe as indicated for albino rats. The results showed that ginger plant seems to have potential in treatment of lung and kidney of diabetic rats;.a finding that could be highly beneficial and further explored in diabetic humans.

\section{References}

Abdulrazaq, N. B., Cho, M. M., Win, N. N., Zaman, R., \& Rahman, M. T. (2012). Beneficial effects of ginger (Zingiber officinale) on carbohydrate metabolism in streptozotocin-induced diabetic rats. Brit. J. Nutr., 108, 1194-1201. http://doi.org/10.1017/S0007114511006635

Adel, S. P. R., \& Prakash, J. (2010). Chemical composition and antioxidant properties of ginger root (Zingiber officinale). J. Med. Plants Res., 4, 2674-2679. http://doi.org/10.5897/JMPR09.464 
Adeniyi, P. O., \& Sanusi, P. A. (2014). Effect of ginger (Zingiber Officinale) extracts on blood glucose in normal and streptozotocin--induced diabetic rats. International Journal of Clinical Nutrition, 2, 32-35. http://doi.org/10.12691/ijen-2-2-2

Al-Amin, Z. M., Thomson, M., Al-Qattan, K. K., Peltonen-Shalaby, R., \& Ali, M. (2006). Anti diabetic and hypoglycemic properties of ginger (Zingiber officinale) in streptozotocin-induced diabetic rats. Brit. J. Nutr., 96, 660-666. https://doi.org/10.1079/BJN20061849

Al-Logmani, A. \& Zari, T. (2011). Long-term effects of Nigella sativa L. oil on some physiological parameters in normal and streptozotocin-induced diabetic rats. J. Diab. Mellit, 1, 46-53. http://doi.org/10.4236/ jdm.2011.13007

Al-Naqeeb, M. A., Thomson, M., Al-Qattan, K. K., Kamel, F., Mustafa, T., \& Ali, M. (2003). Biochemical and histopathological toxicity of an aqueous extract of ginger in female rats. Kuwait J. Sci. Eng., 30, 35-48. https://www.researchgate.net/publication/268743674_Biochemical_and_histopathological_toxicity_of_an aqueous_extract_of_garlic_in_female_rats

Al-Qudah, M. M. A. (2016). Histological and biochemical studies on liver of female rats treated with different concentrations of ethanolic extract of Arum palaestinum. J. Appl. Environ. Biol. Sci., 6, 7-16. Retrieved from https://www.researchgate.net/publication/306118236_Histological_and_Biochemical_Studies_on_Liver_of _Female_Rats_Treated_with_Different_Concentrations_of_Ethanolic_Extract_of_Arum_palaestinum

Al-Qudah, M. M. A., Haddad, M. A., \& EL-Qudah, J. M. F. (2016). The effects of aqueous ginger extract on pancreas histology and on blood glucose in normal and alloxan monohydrate-induced diabetic rats. Biomed Res., https://www.researchgate.net/publication/301649907_The_effects_of_aqueous_ginger_extract_on_pancreas _histology_and_on_blood_glucose_in_normal_and_alloxan_monohydrate-induced_diabetic_rats

Bashir, L., Shittu, O. K., Busari, M. B., Sani, S., \& Aisha, M. I. (2015). Safety evaluation of giant african land snails (Archachatinamarginata) haemolymph on hematological and biochemical parameters of albino rats. $J$. Adva. Med. Pharm.Sci., 3, 122-130. DOI: 10.9734/JAMPS/2015/16393

Elbadri, O., Majzoub, A., \& Musa, O. (2011). Respiratory pressure meta: could it be used as a new device in assessing airway calibre and diagnosis of asthma?. International journal of immunorehabilitation, 13(1), 35.

Elkhishin, I. A., Awwad, I. A. (2009). A study of the cardiovascular toxic effects of Zingiber officinale (ginger) in adult male albino rats and its possible mechanism of action. Mansoura. J. Forensic Med. Clin. Toxicol., 27, 109-125. https://pdfs.semanticscholar.org/c86d/938313eb9e589e9c5fe7dc1887306767fea6.pdf

Elshater, A. A., Salman, M. M. A., \& Moussa, M. M. A. (2009). Effect of ginger extract consumption on levels of blood glucose, lipid profile and kidney functions in alloxan-induced diabetic rats. Egypt Acad. J. Biol. Sci., 2, 153-162. Retrieved from https://www.researchgate.net/publication/237441116_Effect_of_Ginger_Extract_Consumption_on_levels of_blood_Glucose_Lipid_Profile_and_Kidney_Functions_in_Alloxan_Induced-Diabetic_Rats? $\overline{-}$ ev=-public $\overline{\mathrm{Se}}$ archHeader\&_sg=jsw8A_iKYkbaenuG7LE8KEeGOZpsMjvVNOeXF7GJKkOa534kbEcmGhzJWMuVN BuhAdRACuQFbV_VXU

Grant, K. I. (2000). Ginger. Am. J. Health Sys. Pharm., 57, 945-957.

Hamed, M. A., Ali, S. A., \& El-Rigal, N. S. (2012). Therapeutic potential of ginger against renal injury induced by carbon tetrachloride in rats. The Scientific World Journal, Article ID 840421, 12 pages, http://doi.org/10.1100/2012/840421

Jafri, S. A., Abass, S., \& Qasim, M. (2011). Hypoglycemic effect of Ginger (Zingiber officinale) in alloxan-induced diabetic rats (Rattus norvagicus). Pak. Vet. J., 31, 160-162. https://www.researchgate.net/publication/283252230_Hypoglycemic_Effect_of_Ginger_Zingiber_officinal e_in_Alloxan_Induced_Diabetic_Rats_Rattus_norvagicus? ev $=$ publicSearchHeader\&_sg $=5 \mathrm{RPxm} 5 \mathrm{5iBecWH}$ 7RopOLfIqSBGoc9YjMZZd0XAvKi4dpbmy9Mda5Gc6N1DnWUNIAoGH3mAiFbx3Q4M50EI

Mahmoud, M. F., Diaai, A. A., \& Ahmed, F. (2012). Evaluation of the efficacy of ginger, arabic gum, and boswellia in acute and chronic renal failure. Renal Failure, 34, 73-82. http://doi.org/10.3109/0886022X.2011.623563

Ojewole, J. A. O. (2006). Analgesic, anti-inflammatory and hypoglycemic effects of ethanol extract of Zingiber officinale (Roscoe) rhizomes in mice and rats. Phytother. Res., 20, 764-772. http://doi.org/10.1002/ptr.1952 
Portnoi, G., Chng, L. A., Karimi-Tabesh, L., Koren, G., Tan, M. P., \& Einarson, A. (2003). Prospective comparative study of the safety and effectiveness of ginger for the treatment of nausea and vomiting in pregnancy. Am. J. Obstet. Gynaecol., 189, 1374-1377. http://doi.org/10.1067/S0002-9378(03)00649-5

Rafieian-Kopaei, M., \& Nasri, H. (2013). Ginger and diabetic nephropathy. J. Renal. Inj. Prev., 2, 9-10. http://doi.org/10.12861/jrip.2013.05

Rong, X., Peng, G., Suzuki, T., Yang, Q., Yamahara, J., \& Li, Y. (2009). A 35 day gavage safety assessment of ginger in rats. Regul. Toxicol. Pharmacol., 54, 118-123. http://doi.org/10.1016/j.yrtph.2009.03.002

Salim, K. S. (2014). Hypoglycemic property of ginger and green tea and their possible mechanisms in diabetes mellitus. The Open Conference Proceedings Journal, 5, 13-19.

Shalaby, M. A., \& Hamowieh, A. R. (2010). Safety and efficacy of Zingiber officinale roots on fertility of male rats. Food Chem. Toxicol., 48, 2920-2924. http://doi.org/10.1016/j.fct.2010.07.028

Sirvastava, K. C., \& Mustafa, T. (1992). Ginger (zingber officinale) in rhrumatism and muscloskeletal disorders. Med Hypotheses, 39, 342-8. https://www.ncbi.nlm.nih.gov/pubmed/1494322

Suekawa, M., Ishige, A., Yuansa, K., Sudo, K., Aburada, M., \& Hosoya, E. (1984). Pharmacological studies on ginger- Pharmacological actions of pungent constituents of 6-gingerol and 6-shogaol. J. Pharmacoblodyn, 7, 836-848. https://www.ncbi.nlm.nih.gov/pubmed/6335723

Sukalingam, K., Ganesan K., \& Gani, S. B. (2013). Hypoglycemic effect of 6-gingerol, an active principle of ginger in streptozotocin-induced diabetic rats. Journal of Pharmacology and Toxicological Studies, 1, 23-30.

Swaroopa, M. (2013). Effect of ginger extract consumption on renal function during ethanol withdrawal induced-stress. International Journal of Innovative Research in Science, Engineering and Technology, 2, 6412-6418. Retrieved from http://www.rroij.com/open-access/effect-of-ginger-extract-consumption-on-renal-function-during-ethanolwithdrawal-inducedstress-.php?aid=48208

Tang, W., \& Eisenbrand, G. (1992). Drugs of Plant Origin: Chemistry, Pharmacology and Use in Traditional and Modern Medicine. Springer Verlag, Berlin.

Tzeng, T. F., Liou, S. S., Chang, C. J., \& Liu, I. M. (2013). The ethanol extract of Zingiber zerumbet attenuates streptozotocin-induced diabetic nephropathy in rats. Evid. Based Complement Alternat. Med., 1-8. http://doi.org/10.1155/2013/340645

\section{Copyrights}

Copyright for this article is retained by the author(s), with first publication rights granted to the journal.

This is an open-access article distributed under the terms and conditions of the Creative Commons Attribution license (http://creativecommons.org/licenses/by/4.0/). 